J. Lake Sci. (湖泊科学), $2006, \mathbf{1 8}(3): 218-224$

http:// www. jlakes. org. E-mail: jlakes@ niglas. ac.cn

(c) 2006 by Journal of Lake Sciences

\title{
城市富营养化湖泊生态恢复——南京莫愁湖物理生态工程试验
}

\author{
成小英 ${ }^{1,2}$, 李世杰 $^{1}$, 湿培民 $^{1}$
}

(1: 中国科学院南京地理与湖泊研究所,南京 210008)

( 2 : 江南大学工业生物技术教育部重点实验室,无锡 214036)

\begin{abstract}
摘 要: 为了探索城市富营养化湖泊生态修复技术, 2000 年 9 月在南京市莫愁湖物理生态工程试验区内, 开展了隔离外源 污染、覆盖底泥和种植水生植物对湖泊水质平均水平和水体脉动强度影响的比较研究. 试验结果表明, 通过围隔隔离外源 污染可在较短时间内迅速改善湖泊 TN 的平均水平, 但难以提高湖泊生态系统的稳定性; 通过覆盖底泥控制内源污染难以 改善湖泊水质的平均水平, 并且难以提高湖泊生态系统的稳定程度; 种植水生植物不仅能够全面改善湖泊水质的平均水 平, 而且可以提高湖泊生态系统的稳定性. 此外, 富营养化湖泊中, 藻类生长与湖水营养盐浓度并不存在正相关的关系. 因 此, 对城市湖泊富营养化的防治, 在控制外源污染降低营养盐浓度的同时, 应恢复湖泊原有的以水生高等植物为主的生态 系统.
\end{abstract}

关键词:外源污染;底泥;水生植物;高营养化;生态恢复;莫愁湖

\section{Ecological restoration of urban eutrophic lakes - a case study on the physical and ecological engineering in Lake Mochou, Nanjing}

\author{
CHENG Xiaoying ${ }^{1,2}$, LI Shijie ${ }^{1} \&$ PU Peimin ${ }^{1}$ \\ ( 1 :Nanjing Institute of Geography \& Limnology, CAS, Nanjing 210008, P. R. China) \\ ( 2 : Key Laboratory of Industrial Biotechnology, ninistly of Edu cation, Southern Yangtze University, Wuxi 214036, P. \\ R. China)
}

\begin{abstract}
To study the technologies of ecological restoration for urban eutrophic lakes, the comparative experiments of different influence for external pollution isolating, sediment covering and macrophytes planting to the average level of water quality and the fluctuating intensity of water body were carried out in Lake Mochou of Nanjing in September 2000. The results showed that it can improve the average level of TN in a relatively short period but it is different to increase the stability of the lake ecosystem through isolating the external pollution by the soft wall; it cannot improve the average level of the water quality or increase the stability of the lake ecosystem either through isolating the internal pollution by covering the sediment; it can not only improve the average level of the water quality comprehensively, but also increase the stability of the lake ecosystem through macrophyte restoration. Further more, algae growth is not positively correlated with nutrient concentration in eutrophic lakes. In a word, to control the eutrophication of urban lakes, it should be done to restore the pristine ecosystem with macrophytes restoration associated with the priority of external pollution controlling.
\end{abstract}

Keywords : External pollution, sediment; macrophyte; eutrophication; ecological restoration; Lake modovl

湖泊是人类重要的自然资源,城市湖泊在改善城市生态环境等方面起着极其重要的作用 ${ }^{[1]}$. 近十几年 来, 随着城市的扩大和经济的发展,城市湖泊的富营养化过程受到人类活动的强烈影响而大大加速. 目前, 中国多数城市湖泊水体已处于严重富营养化状态 ${ }^{[2]}$, 恢复富营养化城市湖泊生态系统是目前急需解决的

* 香港理工大学、日本河北泻湖泊研究所及中国科学院南京地理与湖泊研究所国际合作项目“旅游湖泊生态修复的 物理生态工程示范研究”与中科院知识创新工程重大项目 (KZCX1 - SW - 12-13) 联合资助. 2005-05-27 收稿; 2005-12-20 收修改稿. 成小英, 女, 1977 年生, 博士:E-mail: chengxiaoy@ hotmail. com. 
问题 ${ }^{[3]}$. 湖泊富营养化防治的基本措施主要包括内源污染控制、外源污染控制和生态控制. 对于外源污染, 一般采取截污与集中处理等措施 ${ }^{[4-6]}$; 对于内源污染,一般采取疏浚底 泥 $^{[7,8]}$ 、覆盖底泥 ${ }^{[9]}$ 、固定营养 盐 ${ }^{[10,11]}$ 等措施; 对于生态控制,一般采取恢复水生植被与控制鱼类等措施 ${ }^{[12,13]}$. 研究显示, 隔离外源污染是 改善湖泊水质的前提, 但难以有效控制湖泊富营养化 ${ }^{[14,15]}$; 覆盖底泥难以抑止浮游植物生长、降低浮游植 物生物量 ${ }^{[16]}$, 例如苏州市若干河道内敷设了水泥板,但水质未见明显好转 ${ }^{[17]}$; 种植水生植物可以有效净化 湖水 ${ }^{[6]}$. 上述研究往往局限于对水质平均水平的影响, 同时相互之间缺少明确的对比, 通过对南京城市湖 泊莫愁湖物理生态工程试验的研究, 我们探讨并比较了隔离湖泊外源污染、覆盖底泥和种植水生植物对水 质平均水平和水体脉动强度的影响, 为城市富营养化湖泊生态恢复提供一定的依据.

\section{1 实验部分}

\section{1 实验地点及自然状况}

莫愁湖位于南京市西南部,在著名的莫愁湖公园内. 水面面 积为 $0.3 \mathrm{~km}^{2}$, 略呈三角形 (图 1 ). 莫愁湖出水口位于湖泊东部, 通往秦淮河;无人湖河渠, 有生活污水排人. 莫愁湖除了供游人 水上娱乐外,湖内还放养了大量鲢、鳙鱼及少量青鱼. 目前, 莫愁 湖水体已处于超富营养化状态. 实验区位于莫愁湖东北隅, 大致 呈西北 - 东南走向, 离岸约 $10 \mathrm{~m}$ (图 1). 该湖区地势平坦, 水深 在 $1.3 \mathrm{~m}$ 左右. 附近湖滨带为草林复合生态系统, 无高大建筑物.

\section{2 实验设计}

用不透水材料、浮体及重压管制成的软隔离带, 围成 5000 $\mathrm{m}^{2}(100 \mathrm{~m} \times 50 \mathrm{~m})$ 的围隔, 与大湖区完全隔离; 并用同样的材料 按图 2 所示将围隔分成 5 个 $1000 \mathrm{~m}^{2}$ 的围区 $(A 、 B 、 C 、 D 、 E)$, 围区 $A$ 又分隔为 32 个 $25 \mathrm{~m}^{2}(5 \mathrm{~m} \times 5 \mathrm{~m})$ 的小围区 $\mathrm{A} 1 、 \mathrm{~A} 2 、 \cdots \mathrm{A} 33$ 和一 个 $200 \mathrm{~m}^{2}(10 \mathrm{~m} \times 20 \mathrm{~m})$ 的中围区 $\mathrm{A} 17$; 中围区 $\mathrm{A} 17$ 用不透水塑料 薄膜覆盖底泥, 与四周围隔紧密相接, 防止了水 - 泥界面的营养 盐释放. 自 2000 年 7 月围隔建成后, 围区 $\mathrm{E} 、$ 中围区 A17 和所有 小围区未引种水生高等植物, 也未作其它处理. 从 2000 年 10 月 初开始, 在围区 B、C、D 内先后引种凤眼莲 (Eichhornia crassipes Solms）、喜早莲子草 [Alternanthera philoxeroides ( Mart. ) Griseb] 、伊乐藻 [Elodea nuttallii (Planch) John]、淔草( Potamogeton crispus Linn) 、微齿眼子菜( Potamogeton maackinus A. Benn.) 等水生 高等植物.

总的来说, $F$ 为开敞水域; $E$ 为隔断外源污染的围区; B、C、D 为种植水生高等植物的围区; 中围区 $\mathrm{A} 17$ 与开敞湖区及其它实 验区完全隔离, 并且底部覆盖了塑料薄膜, 可以认为既无外源污 染, 也无内源污染; 小围区 (如 A11) 则为隔离外源污染的试验 区. 将围区 $\mathrm{E}$ 或小围区 $\mathrm{A} 11$ 与开敞水域 $\mathrm{F}$ 进行对比, 可以研究控 制外源污染对湖泊水质的影响; 将中围区 A17 与小围区 A11 进 行对比, 可以研究覆盖底泥对湖泊水质的影响; 将围区 $\mathrm{C}$ 与围区

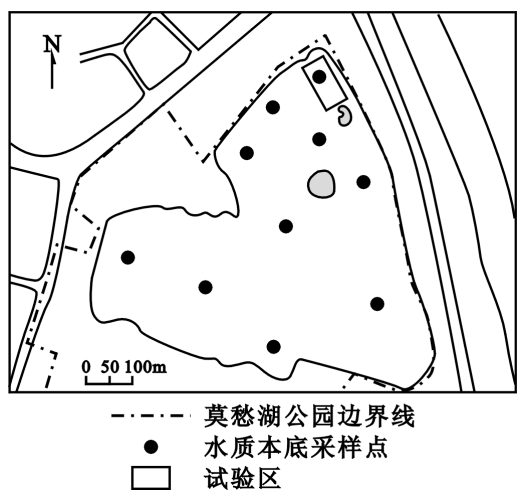

图 1 莫愁湖公园平面图

Fig. 1 The ichnography of Lake Mochou Park

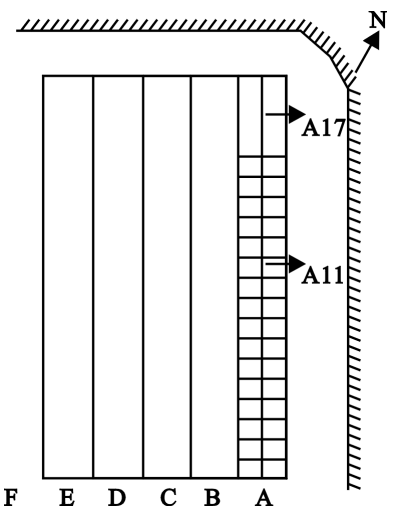

图 2 莫愁湖实验区位置

Fig. 2 The position of the experimental area in Lake Mochou $\mathrm{E}$ 进行对比, 可以研究种植水生高等植物对湖泊水质的影响.

\section{3 水质监测}

采样点: 以围区 $\mathrm{C} 、 \mathrm{E}$ 的南端为其采样点, 以围区 $\mathrm{E}$ 南部的外部为开敞水域 $\mathrm{F}$ 的采样点, 以中围区 $\mathrm{A} 17$ 、 小围区 $\mathrm{A} 11$ 东部边缘的中部为其采样点.

采样频率: 从 2000 年 9 月初到 2001 年 10 月底, 定期对开敞水域 $\mathrm{F}$ 及围区 C、E, 中围区 $\mathrm{A} 17$ 和小围区 


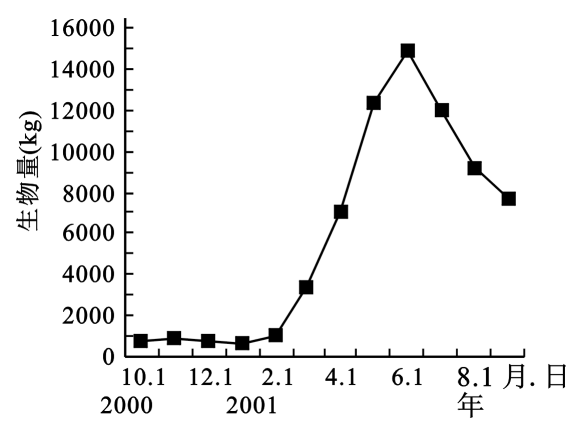

A11 分别取样, 测定 DO、 $\mathrm{NH}_{4}^{+}-\mathrm{N} 、 \mathrm{NO}_{3}^{-}-\mathrm{N} 、 \mathrm{NO}_{2}^{-}-\mathrm{N} 、 \mathrm{PO}_{4}^{3-}-\mathrm{P} 、 \mathrm{TN}$ 、 $\mathrm{TP} 、 \mathrm{COD}_{\mathrm{Mn}} 、 \mathrm{Chla}$ 等.

化学分析方法: 用中国环境监测标准方法 ${ }^{[18]}$ 分析 Chla, 其 它项目依据《湖泊富营养化调查规范》 ${ }^{[19]}$ 规定的方法进行 分析.

\section{2 结果与分析}

\section{1 全湖与围隔水质空间变化}

2000 年 7 月,在围隔建设之前进行水质本底调查, 10 个采 样点均匀分布于全湖 (图 1), 每点分别取表层 (距湖面 $50 \mathrm{~cm}$ )

图 32000 年 10 月至 2001 年 9 月, 围区 B、与底层水样 (距湖底 $50 \mathrm{~cm}$ ). 利用 Hotelling' s Trace 检验方法对 C、D 内水生高等植物各月总生物量的变化 试验结果进行多元方差分析, 分析结果表明,莫愁湖整个水体

Fig. 3 Change of mensal value of the total 内的 $\mathrm{DO} 、 \mathrm{NH}_{4}^{+}-\mathrm{N} 、 \mathrm{NO}_{3}^{-}-\mathrm{N} 、 \mathrm{NO}_{2}^{-}-\mathrm{N} 、 \mathrm{PO}_{4}^{3-}-\mathrm{P} 、 \mathrm{TP} 、 \mathrm{Chla}$ 等主要水 biomass of macrophytes in the enclosure B, C and D from Oct 2000. to Sep 2001. 质指标无显著性差异 (对于水平空间因素变量: $P>0.05$;对于 垂直空间因素变量 $P>0.05)$, 水质相对较为均匀. $5000 \mathrm{~m}^{2}$ 围 隔仅占水面 $16.67 \%$,且分成若干部分, 水质较为一致.
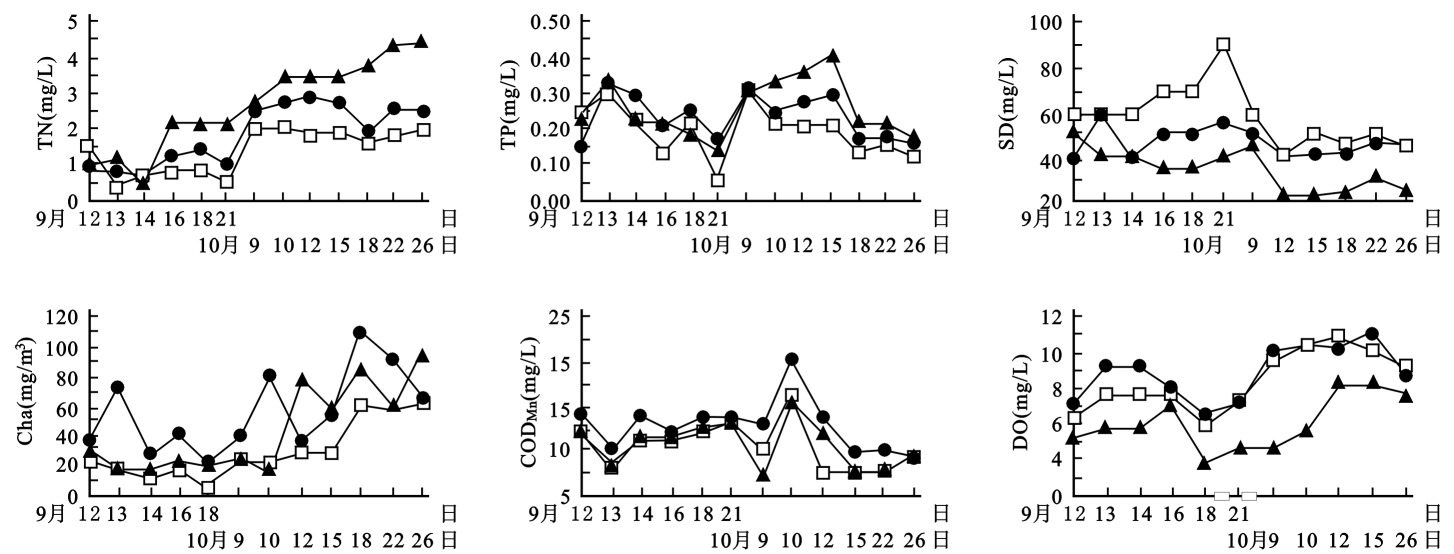

$\triangle \mathrm{A} 17 \bullet \mathrm{A} 11 \quad \square \mathrm{F}$

图 42001 年 $9 、 10$ 月, 开敞水域 F、隔离外源污染的围区 A11、隔离外源污染并覆盖底泥的围区 A17 中, 主要水质指标的变化

Fig. 4 Change of the main indexes of water quality in F, (open are) A17 (external nutrient isolated) and A11 during September and October in 2001

\section{2 水生植被的恢复}

图 3 显示,2000 年秋冬季节,由于引种过程中的人为损伤等原因,引人的水生高等植物生长停滞. 2001 年春季, 水温上升, 水生高等植物开始萌发生长, 水生高等植物生物量呈直线上升趋势; 2001 年夏季, 水生 高等植物生物量达到极大值,水生植被水面覆盖率达到 $80 \%$ 以上;2001 年秋季, 水生高等植物生物量略有 下降,但仍保持较高水平. 反映了引人的水生高等植物恢复良好,实现了自然季相演替.

\section{3 对水质平均水平的影响}

2001 年 9、10 月莫愁湖的资料显示,隔离外源污染的 A11 与开敞水域 $\mathrm{F}$ 内水体的 TN、TP 指标差异极其 显著 $\left(P_{\mathrm{TN}}<0.01, P_{\mathrm{TP}}<0.01\right)$, 营养盐可得到一定降低. $\mathrm{A} 11$ 与 $\mathrm{F}$ 内 $\mathrm{SD}$ 指标差异极其显著 $(P<0.01), \mathrm{A} 11$ 内 $\mathrm{SD}$ 有明显改善; Chla 指标无显著差异 $(P>0.05), \mathrm{A} 11$ 略优于 $\mathrm{F}$. 同时, $\mathrm{A} 11$ 与 $\mathrm{F}$ 内水体 $\mathrm{COD}_{\mathrm{Mn}}$ 指标无显 著差异 $(P>0.05)$, A11 内 DO 明显高于 $\mathrm{F}$ (图 4,表 1$)$. 
自 2000 年 9 月至 2001 年 9 月,隔离外源污染的 $\mathrm{E}$ 与开敞水域 $\mathrm{F}$ 的水质指标平均值显示了类似的变化 趋势 (图 5, 表 2). 与 $\mathrm{F}$ 相比, $\mathrm{E}$ 内水体 $\mathrm{TN}$ 显著降低 $(P<0.05)$, TP 无显著差异 $(P>0.05)$; SD 显著增高 $(P$ $<0.01)$, Chla 无显著差异 $(P>0.05)$; 同时, $\mathrm{E}$ 与 $\mathrm{F}$ 内 $\mathrm{DO}$ 和 $\mathrm{COD}_{\mathrm{Mn}}$ 指标均无显著性差异 $(P>0.05)$.
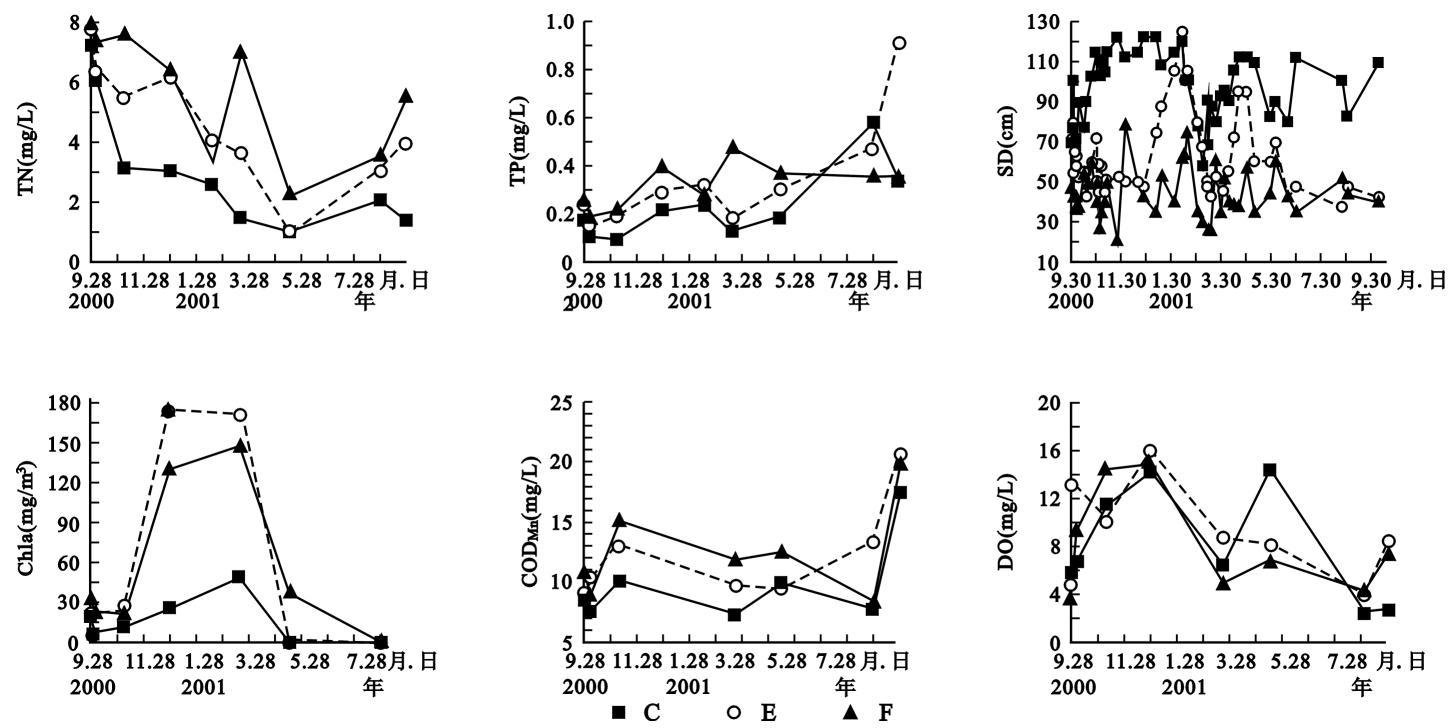

图 52000 年 9 月 -2001 年 9 月,种植水草的围区 C、隔断外源污染的围区 E、

开敞水域 $\mathrm{F}$ 内, 主要水质参数的变化过程

Fig. 5 Change of main indexes of water quality in $\mathrm{C}$ (macrophyte planted), $\mathrm{E}$ (external nutrient isolated) and F( open water) between September 2000 and September 2001

结果表明,控制外源污染可在短期内迅速降低 TN, 但较难减少 TP; 可增高 SD, 但难以减少 Chla; 同时, 可显著改善 DO,但未必能减少围区水体内的有机物质.

2001 年 $9 、 10$ 月,与覆盖底泥的 A17 相比,未覆盖底泥的 A11 内 TP、TN、SD、Chla、COD ${ }_{\mathrm{Mn}}$ 指标均明显好 于 A17, 尤其 Chla 指标与 A17 有极其显著的差异 $(P<0.01)$. 但是, A11 与 A17 内水体 DO 指标无显著性差 异 $(P>0.05)$ (图 4,表 1).

表 12001 年 9 月 -2001 年 10 月,莫愁湖围隔试验结果

Tab. 1 The results of the experiments in Lake Mochou from September 2001 to October 2001

\begin{tabular}{cccccccc}
\hline $\begin{array}{c}\text { 统计 } \\
\text { 特征 }\end{array}$ & 试验区 & $\begin{array}{c}\mathrm{Chla} \\
\left(\mathrm{mg} / \mathrm{m}^{3}\right)\end{array}$ & $\begin{array}{c}\mathrm{TN} \\
(\mathrm{mg} / \mathrm{L})\end{array}$ & $\begin{array}{c}\mathrm{TP} \\
(\mathrm{mg} / \mathrm{L})\end{array}$ & $\begin{array}{c}\mathrm{COD} \\
(\mathrm{mg} / \mathrm{L})\end{array}$ & $\begin{array}{c}\mathrm{DO} \\
(\mathrm{mg} / \mathrm{L})\end{array}$ & $\begin{array}{c}\mathrm{SD} \\
(\mathrm{cm})\end{array}$ \\
\hline \multirow{4}{*}{ 平均值 } & $\mathrm{A} 17$ & 56.50 & 1.82 & 0.2320 & 12.77 & 8.84 & 45.92 \\
& $\mathrm{~A} 11$ & 29.76 & 1.38 & 0.1909 & 10.41 & 8.42 & 58.33 \\
& $\mathrm{~F}$ & 44.17 & 2.66 & 0.2552 & 10.68 & 6.04 & 34.92 \\
\hline \multirow{3}{*}{ 均方差 } & $\mathrm{A} 17$ & 26.30 & 0.80 & 0.0615 & 2.75 & 1.45 & 4.89 \\
& $\mathrm{~A} 11$ & 18.31 & 0.59 & 0.0669 & 2.53 & 1.59 & 13.06 \\
& $\mathrm{~F}$ & 28.24 & 1.23 & 0.0780 & 2.42 & 1.49 & 10.21 \\
\hline
\end{tabular}

试验表明, 与未覆盖底泥相比, 覆盖底泥非但不能降低水体内营养盐含量, 反而显著增加了水体内氮磷 含量, 而且使 Chla 剧增、SD 明显降低. 说明覆盖底泥对水体营养盐的控制作用相当有限,有时甚至比未覆 盖底泥水体的营养盐含量还高; 并且, 覆盖底泥难以遏制浮游藻类生长. 
自 2000 年 9 月至 2001 年 9 月, 种植水草的 $\mathrm{C}$ 内, 除 $\mathrm{PO}_{4}^{3-}-\mathrm{P}$ 外, 其它所有水质指标均有所改善, 尤其 $\mathrm{TN} 、 \mathrm{Chla} 、 \mathrm{SD}$ 和 $\mathrm{COD}_{\mathrm{Mn}}$. 其中, C 内的 Chla 仅为 $15.55 \mathrm{mg} / \mathrm{m}^{3}$, 而隔离外源污染的 $\mathrm{E}$ 内为 $56.95 \mathrm{mg} / \mathrm{m}^{3}$, 开敞 水域 $\mathrm{F}$ 为 $55.99 \mathrm{mg} / \mathrm{m}^{3}$ (图 5 , 表 2). 分析表明, 种植水草可全面改善水质平均水平, 尤其是 SD 和 Chla.

\section{4 对水质变化脉动强度的影响}

统计结果显示, 2001 年 $9 、 10$ 月, A11、A17 和 $\mathrm{F}$ 内水体的水质指标平均变化程度均较大, TN 和 Chla 尤 为强烈 (表 1). A11 内 Chla 的均方差为 $18.31 \mathrm{mg} / \mathrm{m}^{3}, \mathrm{~A} 17$ 为 $26.30 \mathrm{mg} / \mathrm{m}^{3}, \mathrm{~F}$ 为 $28.24 \mathrm{mg} / \mathrm{m}^{3}$, 均大于 $15 \mathrm{mg}$ / $\mathrm{m}^{3}$; 同时, $\mathrm{A} 11 、 \mathrm{~A} 17$ 和 $\mathrm{F}$ 内水体 $\mathrm{TN}$ 的均方差依次为 $0.59 \mathrm{mg} / \mathrm{L}, 0.80 \mathrm{mg} / \mathrm{L}, 1.23 \mathrm{mg} / \mathrm{L}$ : 说明以上三种以浮游 植物为第一生产力的水生生态系统, 水质指标均有较大脉动, 并且由于物理条件的差异 (如有无围隔) 而并 不同步变化. 2001 年 9 月, $\mathrm{A} 11$ 内水温平均值为 $25.26^{\circ} \mathrm{C}, \mathrm{F}$ 为 $25.70^{\circ} \mathrm{C} ; 10$ 月, $\mathrm{A} 11$ 为 $19.06^{\circ} \mathrm{C}, \mathrm{F}$ 为 $19.46^{\circ} \mathrm{C}$. 两种系统内 TP 的比值从极小值 0.43 变化到极大值 1.22 , TN 从 0.26 变化到 1.49 , Chla 从 0.29 变化到 $1.33, \mathrm{SD}$ 从 1.03 变化到 $2.27, \mathrm{DO}$ 从 1.08 变化到 $2.13, \mathrm{COD}_{\mathrm{Mn}}$ 从 0.63 变化到 1.41 , 其中 $\mathrm{TN}$ 和 Chla 波动极 其强烈. 2000 年 9 月到 2001 年 9 月, $\mathrm{E}$ 和 $\mathrm{F}$ 显示了类似的变化趋势 (表 2).

2001 年 $9 、 10$ 月,隔离外源污染的 A11 内, TN、TP、Chla 的均方差均小于开敞水域 F, 而 SD、DO、COD ${ }_{\mathrm{Mn}}$ 的均方差略大于 $\mathrm{F}$ (图 4,表 1). 自 2000 年 9 月至 2001 年 9 月,与开敞水域 $\mathrm{F}$ 相比,隔离外源污染的 $\mathrm{E}$ 内除 $\mathrm{TN}$ 和 DO 的均方差略低于 $\mathrm{F}$ 外, 其他主要水质指标均高于 $\mathrm{F}$; 其中, $\mathrm{E}$ 内 $\mathrm{TP}$ 的均方差与 $\mathrm{F}$ 相差 $0.13 \mathrm{mg} / \mathrm{L}$, Chla 相差 $19.75 \mathrm{mg} / \mathrm{m}^{3}, \mathrm{SD}$ 相差 7.38m(图 5 , 表 2). 结果表明, 单纯控制外源污染难以全面增高水生生态系 统的稳定性, 有些指标的脉动强度甚至更大.

2001 年 $9 、 10$ 月,与未覆盖底泥的 A11 相比, 覆盖底泥的 A17 内 SD 的均方差明显小于 A11, DO 和 TP 略小于 $\mathrm{A} 11$, 其它水质指标均显著大于 A11. 其中, $\mathrm{A} 17$ 内 Chla 的均方差较 $\mathrm{A} 11$ 大 $7.99 \mathrm{mg} / \mathrm{m}^{3}$ (图 4, 表 1). 分析表明, 通过覆盖底泥控制湖泊内源污染非但较难改善水生生态系统的稳定性, 有时甚至加剧了某些水 质指标的脉动强度, 特别是 Chla.

自 2000 年 9 月至 2001 年 9 月,种植水草的 C 内, TN、SD 和 DO 的均方差均大于隔离外源污染的 $\mathrm{E}$ 和 开敞水域 $F$; 然而, C 内的 Chla 的均方差仅为 $15.22 \mathrm{mg} / \mathrm{m}^{3}$, 远远小于 $\mathrm{E}$ 的 $73.16 \mathrm{mg} / \mathrm{m}^{3}$ 和开敞水域 $\mathrm{F}$ 的 $53.41 \mathrm{mg} / \mathrm{m}^{3}$ (图 5 , 表 2). 上述结果显示, 在全面改善水质平均水平的同时, 种植水草虽然未能全面削弱水 中营养物质含量的脉动强度, 却大大增加了生态系统的稳定程度.

表 $22000 / 9-2001 / 9$, 莫愁湖试验区 C、E、F 水质变化

Tab. 2 Change of water quality in C, E and F in Lake Mochou between September 2000 and September 2001

\begin{tabular}{lccccccccccc}
\hline $\begin{array}{c}\text { 统计 试验 } \\
\text { 特征 场所 }\end{array}$ & $\begin{array}{c}\mathrm{Chla} \\
\left(\mathrm{mg} / \mathrm{m}^{3}\right)\end{array}$ & $\begin{array}{c}\mathrm{TN} \\
(\mathrm{mg} / \mathrm{L})\end{array}$ & $\begin{array}{c}\mathrm{TP} \\
(\mathrm{mg} / \mathrm{L})\end{array}$ & $\begin{array}{c}\mathrm{NO}_{2}^{-}-\mathrm{N} \\
(\mathrm{mg} / \mathrm{L})\end{array}$ & $\begin{array}{c}\mathrm{NO}_{3}^{-}-\mathrm{N} \\
(\mathrm{mg} / \mathrm{L})\end{array}$ & $\begin{array}{c}\mathrm{NH}_{4}^{+}-\mathrm{N} \\
(\mathrm{mg} / \mathrm{L})\end{array}$ & $\begin{array}{c}\mathrm{PO}_{4}^{3-}-\mathrm{P} \\
(\mathrm{mg} / \mathrm{L})\end{array}$ & $\begin{array}{c}\mathrm{COD}_{\mathrm{Mn}} \\
(\mathrm{mg} / \mathrm{L})\end{array}$ & $\begin{array}{c}\mathrm{DO} \\
(\mathrm{mg} / \mathrm{L})\end{array}$ & $\begin{array}{c}\mathrm{SD} \\
(\mathrm{cm})\end{array}$ \\
\hline 平 & $\mathrm{C}$ & 15.55 & 3.10 & 0.23 & 0.46 & 0.78 & 1.63 & 2.13 & 9.81 & 8.04 & 96.73 \\
均 & $\mathrm{E}$ & 56.95 & 4.61 & 0.34 & 1.27 & 0.92 & 2.34 & 0.08 & 12.14 & 9.13 & 62.99 \\
值 & $\mathrm{F}$ & 55.99 & 5.65 & 0.32 & 1.73 & 0.99 & 3.40 & 0.08 & 12.44 & 8.23 & 44.18 \\
\hline 均 & $\mathrm{C}$ & 15.22 & 2.03 & 0.15 & 1.11 & 0.74 & 1.39 & 0.22 & 3.31 & 4.52 & 21.95 \\
方 & $\mathrm{E}$ & 73.16 & 1.93 & 0.22 & 3.41 & 0.70 & 1.82 & 0.06 & 3.77 & 3.77 & 19.6 \\
差 & $\mathrm{F}$ & 53.41 & 1.99 & 0.09 & 4.71 & 0.77 & 1.99 & 0.07 & 3.70 & 4.10 & 12.23 \\
\hline
\end{tabular}

\section{3 结果}

由于 $\mathrm{SD}$ 易于监测,每周至少监测一次. 对 2000 年 9 月至 2001 年 10 月的 SD 数据进行多对配对变量的 $\mathrm{T}$ 检验, 结果表明 $\mathrm{B} 、 \mathrm{C} 、 \mathrm{D}$ 的 SD 无显著性差异, $\mathrm{A} 3 、 \mathrm{~A} 11 、 \mathrm{~A} 15$ 的 SD 也无显著性差异. 由于 SD 是与湖泊营养 状态变化关系最为密切的一项参数, 可以认为, 围区 C 与小围区 A11 的结果均具有代表性.

浮游植物生物量和水体透明度是表征湖泊富营养化的重要指标, Chla 是表示浮游植物生物量的一种方 法. 莫愁湖物理生态工程的试验结果显示: 隔离外源污染可在短期内迅速降低 TN, 但不易减少 TP; 可使 SD 
有所上升, 但难以遏制浮游藻类的生长. 覆盖底泥则难以减少氮磷含量, 并使 Chla 剧增、SD 明显降低. 这两 种方法均难以减少湖水中的磷, 达到抑制浮游藻类生长、控制城市湖泊富营养化的目的. 种植水生高等植物 不但可以减少氮磷含量, 而且可使 Chla 显著减少、SD 显著增高, 换句话说, 种植水生高等植物可以全面改 善湖泊水质的平均水平.

通过软隔离带隔离外源污染或通过覆盖底泥控制内源污染的水生生态系统,水质指标脉动程度仍然较 大,生态系统稳定性极差. 水生高等植物种植在显著降低 Chla 平均水平的同时, 明显增高了 Chla 的稳定程 度,大大改善了水生生态系统的稳定性.

总的来说,通过软隔离带隔离外源污染可在较短时间内迅速改善湖泊部分营养物质的平均水平,但是 难以提高水生生态系统的稳定程度; 通过覆盖底泥控制内源污染不但难以改善湖泊水质的平均水平, 而且 也难以提高水生生态系统的稳定程度; 而种植水生高等植物不仅能够全面改善湖泊水质的平均水平, 而且 可以提高水生生态系统的稳定性.

\section{4 讨论}

使用围隔隔离外源污染仅仅控制了外源污染的输人,底泥释放并未减少;一些实验室研究表明,在隔离 外源污染的条件下, 湖泥磷释放明显 ${ }^{[14]}$. 因而,通过围隔控制外源污染难以减少湖水 TP 的含量.

覆盖底泥隔离内源污染,在减少水中营养物质的同时,破坏了湖泊生态系统的完整性,减少了底栖生物 与微生物, 通过降水降尘进人水体的营养物质难以通过生物作用排出水体; 同时, 底栖生物与微生物对浮游 藻类的遏制作用也显著减弱, 导致浮游藻类剧增、SD 明显降低、富营养化程度加剧. 因此, 应辩证的看待底 泥的作用, 底栖生物与微生物对水质的净化作用不应忽视, 通过覆盖底泥控制内源污染不是一种良好的 方法.

此外, 比较水体营养盐浓度变化与 Chla 或 SD 的相互关系, 可以看出富营养化湖泊中藻类的生长与湖 水营养盐浓度并不存在正相关的关系; 并且中国富营养化湖泊常见的藻类优势种, 对营养盐的耐受限较宽, 在湖水营养盐浓度较低时也能生长繁殖, 甚至形成水华 ${ }^{[14]}$. 因而, 即使通过控制污染源大幅减少了湖水营 养物质含量,如果不采取其它措施,也难以控制浮游藻类生长和湖泊富营养化.

实际上, 在富营养化湖泊中, 通过隔离外源污染或者覆盖底泥减少营养物质并未从根本上改变以浮游 植物为主要初级生产者的水生生态系统结构, 并未改变湖内营养物质的主要生物地球化学循环过程, 因而 隔断外源污染或者覆盖底泥虽然可在一定程度上减少湖内营养物质, 湖泊生态系统的稳定性仍然极差, 这 通过 Chla 的脉动程度表现了出来. 在富营养化湖泊种植水草, 使湖泊成为以水生高等植物为主要初级生产 者的水生生态系统, 能够改变湖内营养物质的生物地球化学循环过程, 从而抑制浮游藻类的生长、提高水生 生态系统的稳定性.

因此,对城市湖泊富营养化的防治,在控制水体外源污染降低营养盐浓度的同时,应着眼于中性的恢复 湖泊原有的以水生高等植物为主的生态系统,并维持其动态平衡.

\section{5 参考文献}

[1] 孙 刚,盛连喜. 湖泊富营养化治理的生态工程. 应用生态学报, 2001,12(4):590-592.

[2] 赵生才. 我国湖泊富营养化的发生机制与控制对策. 地球科学进展, 2004,19(1):138-140.

[3] 谢礼国, 郑怀礼. 湖泊富营养化的防治对策研究. 世界科技研究与发展, 2004,26(7):7-11.

[4] 朱季文,季子修,蒋自巽. 太湖湖滨带的生态建设. 湖泊科学,2002,14(1): $77-82$.

[5] 粱 威, 吴振斌. 人工湿地对污水中氮磷的去除机制研究进展. 环境科学动态, 2001,3:32-37.

[6] Perrow M R, Davy A J. Handbook of Ecological Restoration. Cambridge: Cambridge University Press, 2002 : $53-62$.

[7] O'Meara J, Murray J. Restoration of an urban lake: the newburgh lake project. New Orleans: Wat Environ Federation WEFTEC'99, 1999:1 - 10.

[8] 菐培民, 王国祥. 底泥疏浚能控制湖泊富营养化吗? 湖泊科学, 2000,12(3) :269-279. 
[9] Stüben D, Walpersdorf E. Application of lake marl at lake Arendsee, NE Germany first results of a geochemical monitoring during the restoration experiment. The Sci of the Total Environ, 1998, 218: 33 - 44.

[10] Quaak M, van der Does J, Boers P, et al. A new technique to reduce internal phosphorus loading by in-lake phosphate fixation in shallow lakes. Hydrobiologia, 1993, 253: 337 - 344.

[11] Varjo E, Liikanen A. A new gypsum-based technique to reduce methane and phophorus release from sediments of eutrophied lakes: Gypsum treatment to reduce internal loading. Wat Res, 2003, 37: 1 - 10.

[12] Brouwer E, Bobbink R. Restoration of aquatic macrophyte vegetation on acidified and eutrophied softwater lakes an overview. Aquatic Botany, 2002, 73: 405 - 431.

[13] Qiu D, Wu Z. The restoration of aquatic macrophytes for improving water quality in a hypertrophic shallow lake in Hubei Province China. Ecol Engineering, 2001, 18: 147 - 156.

[14] 王国祥,誉培民. 若干人工调控措施对富营养化湖泊藻类种群的影响. 环境科学, 1999,20(2):71-74.

[15] Hosper S H. Stable states, buffers and switches: an ecosystem approach to the restoration and management of shallow lakes in Netherlands. Wat Sci Tech, 1998, 37(3): $151-164$.

[16] Jacoby J M, Gibbons H L, Stoops K B. Response of a shallow, polymictic lake to buffered alum treatment. Lake Reservoir Manage, 1994, 10(2) : 103 - 112.

[17] 王国祥. 富营养化湖泊生态修复的物理生态工程及其机理 [学位论文]. 中国科学院南京地理与湖泊 研究所, 1999:1-17.

[18] 国家环境保护局《水和废水监测分析方法》编委会主编. 水和废水监测分析方法. 北京: 中国环境科学 出版社, $1989: 246-285$.

[19] 金相灿, 屠清瑛主编. 湖泊富营养化调查规范. 北京: 中国环境科学出版社, 1990:138-207. 